\author{
Henryk Grajek, Justyna Jonik, Leszek Rutkowski, Marcin Purchała, Tomasz Wawer \\ Military University of Technology, Institute of Chemistry \\ ul. Kaliskiego 2, 00-908 Warszawa, hgrajek5819@wp.pl
}

\title{
THE OPTIMISATION OF CHROMATOGRAPHIC CONDITIONS FOR THE DETERMINATION OF ACCEPTOR-DONOR PROPERTIES OF GRAPHENE OXIDE AND REDUCED GRAPHENE OXIDE
}

\begin{abstract}
The oxidised and reduced graphene samples (having different surface functionalities) were studied by inverse gas chromatography to characterise their acceptor-donor properties. The DN values denoting the donor number in the Gutmann scale and the $\mathrm{AN}^{*}$ values denoting the acceptor number in the Riddle-Fowkes scale have been chosen in the estimation of the electron-acceptor parameter $\mathrm{K}_{\mathrm{A}}$ and electron-donor parameter $\mathrm{K}_{\mathrm{D}}$ values.
\end{abstract}

Key words

Inverse gas chromatography, reduced and oxidized graphene, acceptor-donor properties.

\section{Introduction}

Throughout the history of mankind, each period has taken its name from the material that was commonly in use at the time, such as stone, bronze and iron. Already in 1962, Boehm et al. described a method of synthesis a carbon foil of $100 \AA$ thickness [1]. But only in 2004, the two-dimensional materials period began a new phase of material engineering [2,3]. The material is graphene, which can change the contemporary electronic industry because of its unique properties. Since the first isolation from graphite, graphene became a very popular material. By 2012, 8000 articles were published on the subject [4].

Graphene is a one-atom-thick planar sheet of $\mathrm{sp}^{2}$-bonded carbon atoms that are densely packed in a honeycomb crystal lattice. Apart from that it is the main part of the other allotropic forms of carbon, such as fullerenes or nanotubes $[5,6]$.

Many unusual properties of graphene have been disclosed since its isolation. For example, researchers have observed a high mobility of charges (electrons and positive holes), c.a. $230000 \mathrm{~cm}^{2} / \mathrm{V}^{*} \mathrm{~s}$ [7], a thermal conductivity, c.a. $5000 \mathrm{~W} / \mathrm{m}^{*} \mathrm{~K}$ [8], Young's modulus value, c.a. 1 TPa [9], and an ultimate tensile (and bending) strength, c.a. $130 \mathrm{GPa}$ [9].

It is worth mention that graphene has many surface functionalities, such as carboxylic and ketone groups, which covalently attach many biological molecules and determines the possibilities in biodetectors. Moreover, chemically modified graphene (CMG) is a promising material for energy storage. Graphene oxide can be employed in environmental protection. Thanks to its surface, it can adsorb radionuclides from water and improve its quality. Because graphene preserves spin polarization, it can be used to create low-strength spin contacts, which could be compatible with ferromagnetic metal and a semiconductor. High catalytic activity and exceptional electrical conductivity make graphene possible for use in photovoltaic cells. Graphene batteries can convert up to $7.8 \%$ of solar energy into electricity [10]. It has been proven that the deposition of graphene from the gas phase on a metal surface causes corrosion processes to proceed much slower. Therefore, graphene can be employed to make anti-corrosion coatings [11,12].

\section{Materials and methods}

The study was focused on the samples of oxidized (GO), PCode: 1001819253, Sigma Aldrich, and reduced (rGO) graphene, PCode: 1001888758, Sigma Aldrich. The inverse gas chromatography tests at infinite dilution (IGC-ID) were performed by means of the Unicam type 610 apparatus with a high sensitivity of flame ionization detector with the AC-DC converter. To accomplish the infinite dilution conditions, vapours of the testing substances were injected into a column by means of the Hamilton type $7000.5 \mathrm{KH}$ syringe. The chromatographic peaks were acquired at a sampling rate of $25 \mathrm{~Hz}$. Chromatograph's software Unicam 4880, Microsoft Office 
Excel 2010, Syntat Software TableCurve 2D v5.01 and Daniel G. Hyams CurveExpert Professional 2.0 were used for all calculations. The chromatographic conditions are collated in Table 1.

Table 1. Chromatographic conditions

\begin{tabular}{|l|l|}
\hline Temperature of injector & $155^{\circ} \mathrm{C}$ \\
\hline \multirow{2}{*}{ Temperatures of column } & for GO: $150,145,140,135,130{ }^{\circ} \mathrm{C}$ \\
\cline { 2 - 2 } & for $\mathrm{rGO}: 150,145,140{ }^{\circ} \mathrm{C}$ \\
\hline Temperature of detector & $155^{\circ} \mathrm{C}$ \\
\hline Carrier gas used & helium N5.2, pure for analysis \\
\hline Carrier gas flow-rate & $20 \pm 0.5 \mathrm{~cm}^{3} / \mathrm{min}$ \\
\hline \multirow{2}{*}{ Mass of column filling } & $\mathrm{GO}: 0.1251 \mathrm{~g}$ \\
\cline { 2 - 2 } & $\mathrm{rGO}: 0.0217 \mathrm{~g}$ \\
\hline Detector's sensitivity & $10 \mathrm{mV}$ \\
\hline \multirow{2}{*}{ Specific surface area $\mathrm{S}_{\mathrm{BET}}$} & $\mathrm{GO}: 2 \mathrm{~m}^{2} / \mathrm{g}$ \\
\cline { 2 - 2 } & $\mathrm{rGO}: 321 \mathrm{~m} / \mathrm{g}$ \\
\hline \multirow{3}{*}{ Testing substances } & $\begin{array}{l}\mathrm{n} \text {-pentane, } \mathrm{n} \text {-hexane, n-heptane, n-octane (only for GO), } \\
\text { dichloromethane, chloroform, carbon tetrachloride, } \\
\text { acetonitrile, ethyl acetate, diethyl ether, tetrahydrofuran }\end{array}$ \\
\hline
\end{tabular}

Source: Author's

The optimisation of the chromatographic conditions for elution of probes on graphene samples consists in such selection of them that all relevant properties of the tested graphene samples are thoroughly examined. Nevertheless, simultaneously with the aforesaid conditions to make up for the valuable observation and results received by Stankovich and his coworkers [13].

The resulting file contained all flow disturbance caused by the sample being injected into the carrier gas stream. The data obtained were loaded into the TableCurve 2D v5.01 software (prod. Syntat Corp.) that enables the description of the data set by a suitable mathematical function to obtain the highest value of the nonlinear correlation coefficient. The following mathematical functions were employed for the description of the primary elution data (Eq. 1 - the P4 function and Eq.2 - the ExtraVal4T function) [14].

$c(t)=h_{\max } \frac{\left[1+\frac{\left(t-\frac{w s_{2}}{2 s_{1}}-t_{R}^{s c}\right)^{2}}{w^{2}}\right]^{-s_{1}} \exp \left[-s_{2}\left(\tan ^{-1}\left(\frac{t-\frac{w s_{2}}{2 s_{1}}-t_{R}^{s c}}{w}\right)+\tan ^{-1}\left(\frac{s_{2}}{2 s_{1}}\right)\right)\right]}{\left(1+\frac{s^{2}}{4 s_{1}^{2}}\right)^{-s_{1}}}$

$c(t)=h_{\max } * \exp \left[\frac{-t+t_{r}^{s c}+w-w s * \exp \left(\frac{-t+w \ln s-t_{R}^{s c}}{w}\right)}{w s}\right]$

where:

$c(t)$ - the time dependent concentration of the testing substance,

$h_{\max }$ - the height of the elution peak,

$t$ - the elution time of the testing substance,

$w$ - the width of the elution peak,

$\mathrm{s}$ - the parameter related to the symmetry of the elution peak,

$t_{R}{ }^{s c}$ - the retention time of the centre of gravity of the elution peak.

Based on the retention times of the centres of gravity of the elution peaks for the testing substances (which were calculated by applying the equations (1) and (2)), the values of the specific retention volumes, referred to 1 gram of the column filling and its specific surface area, were calculated. The values of the specific retention volumes calculated in this way are the physicochemical constants (Eqs 3, 4 and 5) [15]. 
$V_{g}=\frac{V_{N}}{m} * \frac{T_{C}}{273,15}$

$V_{N}=j_{3}^{2}\left(\frac{p_{0}-p_{H_{2}} O}{p_{0}}\right) F_{C}\left(t_{R}-t_{M}\right) \frac{T_{C}}{T_{0}}$

$j=\frac{3}{2} \frac{\left[\left(\frac{p_{i}}{p_{0}}\right)^{2}-1\right]}{\left[\left(\frac{p_{i}}{p_{0}}\right)^{3}-1\right]}$

where:

$\mathrm{V}_{\mathrm{g}}$ - the specific retention volume,

$\mathrm{V}_{\mathrm{N}}$ - the net retention volume,

$\mathrm{m}$ - the mass of column filling,

$\mathrm{T}_{\mathrm{C}}$ - the column temperature,

j- James-Martin compressibility factor,

$\mathrm{p}_{0}$ and $\mathrm{T}_{0}$ - atmospheric pressure and temperature,

$\mathrm{p}_{\mathrm{H} 2 \mathrm{O}}$ - the pressure of water vapour at environment temperature,

$\mathrm{F}_{\mathrm{C}}$ - the volumetric flow rate of the carrier gas through the column, measured by soap flow-meter at the constant column temperature,

$t_{R}$ and $t_{M}$ - the retention time of the centre of gravity of the probe and the hold-up time,

$\mathrm{p}_{\mathrm{i}}$ - the inlet pressure at the column.

The molar differential enthalpy and entropy of adsorption can be estimated from the temperature dependencies of the specific retention volumes referred to 1 gram of the tested material and its specific surface area or the adsorption virial coefficients. The following equation can be employed for the aforementioned calculations [15]:

$\ln \frac{V_{g\left(T_{C}\right)}^{1 g}}{T_{C}}=\frac{-\Delta H_{A D S}}{R} \frac{1}{T_{C}}+\frac{\Delta S_{A D S}}{R}+\ln \left(R * S_{B E T} * m\right)$

where:

$V_{g\left(T_{C}\right)}^{1 g}$ - the specific retention volume referred to the centre of gravity of the elution peak and to $1 \mathrm{~g}$ of column filling,

$\Delta \mathrm{H}_{\mathrm{ADS}}$ - the molar differential enthalpy of adsorption,

$\mathrm{R}$ - gas constant $\left(8,314 \mathrm{~J} / \mathrm{mol}^{*} \mathrm{~K}\right)$,

$\Delta \mathrm{S}_{\mathrm{ADS}}$ - the molar differential entropy of adsorption,

$\mathrm{S}_{\mathrm{BET}}$ - the specific surface area of GO and rGO.

Adsorption as a spontaneous process on the solid surface is accompanied by a decrease of the standard energy of the system tested. The value of the total free energy transfer of one mole of substance from the gas phase to the standard state on the graphene surface can be estimated by employing the following equation $\Delta G_{A D S}=-R * T_{C} * \ln \left(\frac{p_{s, g}}{\pi_{S} S_{B E T}} V_{g(T C)}^{1 g}\right)$ [15]. In this dependency $\Delta G_{A D S}$ is the molar differential Gibbs free energy of adsorption, $p_{s, g}$ is the reference pressure of $1 \mathrm{~atm}\left(101325 \mathrm{~N} / \mathrm{m}^{2}\right)$ and $\pi_{s}$ is the two-dimensional pressure of the adsorbed state $\left(0,338 * 10^{-3} \mathrm{~N} / \mathrm{m}^{2}\right)$.

The molar differential Gibbs free energy of adsorption characterizes the interaction of adsorbate molecules in the mobile phase with the outermost atoms on the adsorbent surface and the interaction of adsorbate molecules in the mobile phase with the atoms on its surface. In the case of a well-defined chromatographic process, the increase in the free energy of adsorption referred to the methylene group in n-alkane chain can be estimated from the slope of the natural logarithm of the net retention volume by using the following equation $-\Delta G_{A D S}^{C H_{2}}=R T_{C} \ln \left(\frac{V_{N+1}^{\left(C_{n+1} H_{2 n+4}\right)}}{V_{N}^{\left(C_{n+1} H_{2 n+2}\right)}}\right)$ [15], where $\Delta G_{A D S}^{C H_{2}}$ is the molar differential Gibbs free energy of adsorption of a methylene group in an n-alkane molecule, $V_{N+1}^{\left(C_{n+1} H_{2 n+4)}\right)}$ and $V_{N}^{\left(C_{n+1} H_{2 n+2}\right)}$ are the net retention volumes of consecutive $\mathrm{n}$-alkanes having $\mathrm{n}+1$ and $\mathrm{n}$ methylene groups in their molecules, respectively. 
The $\Delta G_{A D S}^{C H_{2}}$ values allow us to estimate the magnitude needed for surface energetic characteristics, i.e., the dispersive component of the surface free energy, $\gamma_{S}^{D}$. The aforesaid dependency is based on the $\Delta G_{A D S}^{C H_{2}}$ increment per methylene group for subsequent $n$-alkanes consecutive. The values of the dispersion component of the surface free energy were determined by employing the following dependency (Eq.7) $[16,17,18]$.

$\gamma_{S}^{D}=\frac{1}{4 \gamma_{C H_{2}}}\left(\frac{\Delta G_{A D S}^{C H_{2}}}{N_{A} \omega_{C H_{2}}}\right)^{2}$

where:

$\gamma_{S}^{D}$ - the dispersive component of the free energy of the liquid or testing substance injected,

$\gamma_{\mathrm{CH}_{2}}$ - the surface energy of polyethylene-type polymers with a finite molecular weight, suggested by Voelkel $\left(\gamma_{\mathrm{CH}_{2}}=35,6+0,058[293-\mathrm{TC}(K)]\right)[16]$,

$N_{A}$ - Avogadro constant,

$\omega_{\mathrm{CH}_{2}}$ - the sitting area of methylene group.

The chromatographic tests of the acid-base interactions are only possible by testing substances having nucleophilic and electrophilic groups or atoms. In the case of the IGC tests, if the adsorbate used exhibits acidic properties, it is possible to estimate the basic properties of the graphene samples. The characteristic of the acceptor-donor properties of any system require the estimation of the total free energy of adsorption $\triangle G_{A D S}$, which is sum of the component for the specific interactions $\Delta G_{A D S}^{S P}$ and other interactions than specific $\Delta G_{A D S}^{v d W}[16]$.

The specific interactions:

- acceptor-donor interactions,

- interactions between permanent dipoles,

- induced dipole-permanent dipole,

- hydrogen bonds interactions.

For chromatographic evaluation of the acceptor-donor properties of the adsorbent, the testing substances with strictly defined acid-base properties, which behave:

- as donor, i.e., they are donating an electron, or

- as acceptor, i.e., they are taking an electron.

To perform the acid-base characterization of the solid surface, it is necessary to determine the magnitude of the effects for the system: testing substance-adsorbent. Considering all the predetermined values of the retention times or the free energy of adsorption values, all testing substances can be classified on the basis of their interactions with the surface functionalities present on both sample surfaces:

- adsorbates molecules interacting with weak force: $n$-alkanes,

- adsorbates molecules interacting with middle force: dichloromethane, chloroform, carbon tetrachloride,

- adsorbates molecules strongly interacting: acetonitrile, ethyl acetate, diethyl ether, tetrahydrofuran.

The surface properties of a different adsorbent can be characterized using the $\mathrm{K}_{\mathrm{A}}$ (characterizing the acceptor properties) and $K_{D}$ (characterizing the donor properties) parameters estimated on the thermodynamic functions (Eq.8) [19].

$\Delta H_{A D S}^{S P}=K_{A} * D N+K_{D} * A N^{*}$

where:

$\Delta H_{A D S^{-}}^{S P}$ the value of the specific component of the molar differential enthalpy of adsorption described by the following equation $\frac{\Delta G_{A D S}^{S P}}{T c}=\frac{\Delta H_{A D S}^{S P}}{T c}+\operatorname{const}[15], D N$ is the Gutmann donor number [20], $K_{A}$ is the parameter characterizing the acceptor properties, $A N^{*}$ is the Riddle-Fowkes acceptor number [21] and $K_{D}$ is the parameter characterizing the donor properties. 
The application the DN and $\mathrm{AN}^{*}$ parameters in the physicochemical calculations based on the IGC results is mandatory because their empirical values unambiguously illustrate their fundamental source in the interaction strength of lone and shared electron pairs, and they treat each functionality (or molecule) as being either an acid or a base [22].

Voelkel has proposed a method of determining the values of the $\mathrm{K}_{\mathrm{A}}$ and $\mathrm{K}_{\mathrm{D}}$ parameters based on the values of the specific component of the free energy of adsorption that contain the entropy factor (Eqs 9 and 10) [19].

$\Delta G_{A D S}^{S P}=\Delta H_{A D S}^{S P}+T_{C} * \Delta S_{A D S}^{S P}$

$\Delta G_{A D S}^{S P} \cong K_{A} * D N+K_{D} * A N^{*}$

where:

$\Delta S_{A D S}^{S P}$ - the value of the molar differential entropy of adsorption of specific interactions.

The $K_{A}$ and $K_{D}$ values have been calculated for the graphene samples tested [19]:

a) without taking into account the entropic effect (Eq. 11):

$\frac{\left(-\Delta H_{A D S}^{S P}\right)_{i}}{A N_{i}^{*}}=K_{A} \frac{D N_{i}}{A N_{i}^{*}}+K_{D}$

b) with accounting for the entropic effect (Eq. 12):

$\frac{\left(-\Delta G_{A D S}^{S P}\right)_{i}}{A N_{i}^{*}} \cong K_{A} \frac{D N_{i}}{A N_{i}^{*}}+K_{D}$

where:

$i$ - subscript denoting the adsorbate used.

\section{Results and discussion}

Based on the acquired elution data performed at ideal, nonlinear chromatographic conditions, the values of the specific retention volume have been determined by using equations (3), (4) and (5). Based on the retention data obtained by using the ExtraVal4T function for the description of peak profiles, the $\ln (\mathrm{Vg} / \mathrm{Tc})=\mathrm{f}(1 / \mathrm{Tc})$ dependencies for the GO sample have been prepared and presented in Figs 1, 2 and 3.The column temperature increase causes the decrease of the specific retention volume. However, the increase of the molecular mass causes an increase of the specific retention volume. The $\ln (\mathrm{Vg} / \mathrm{Tc})=\mathrm{f}(1 / \mathrm{Tc})$ dependency is commonly employed for the determination of the molar differential enthalpy and entropy of adsorption.

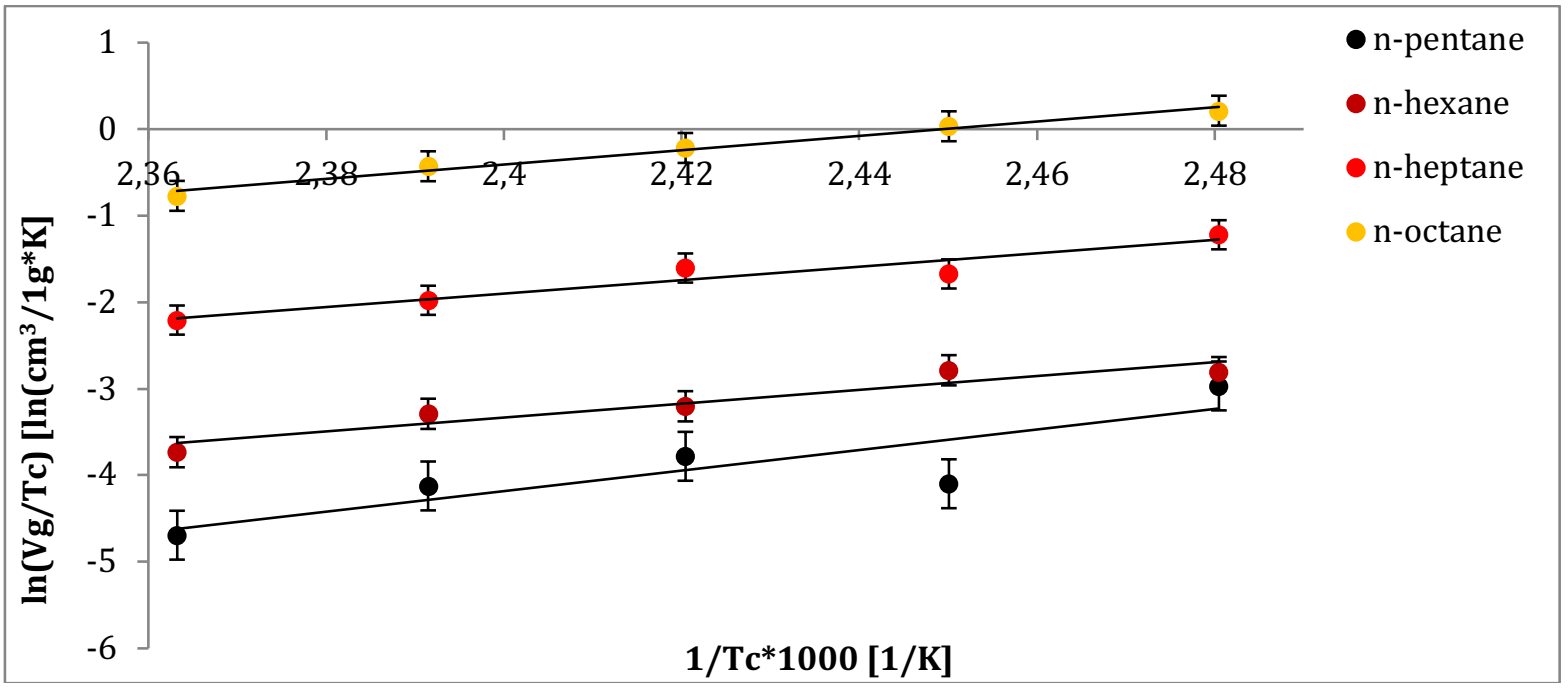

Fig. 1. The $\ln (\mathrm{Vg} / \mathrm{Tc})=\mathrm{f}(1 / \mathrm{Tc})$ dependencies for the $\mathrm{GO}$ ( $\mathrm{n}$-alkanes)

Source: Author's 


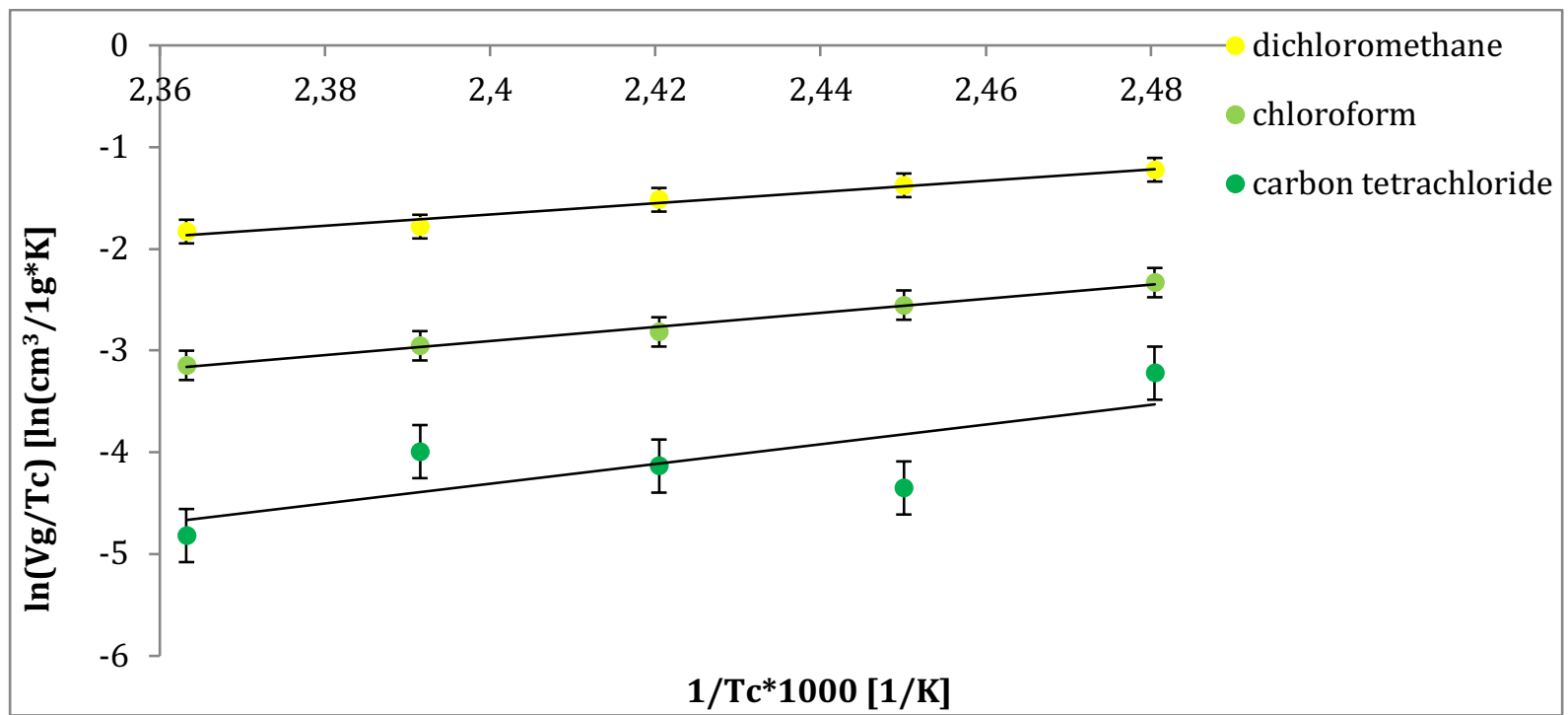

Fig. 2. The $\ln (\mathrm{Vg} / \mathrm{Tc})=\mathrm{f}(1 / \mathrm{Tc})$ dependencies for the $\mathrm{GO}$ (dichloromethane, chloroform, carbon tetrachloride) Source: Author's

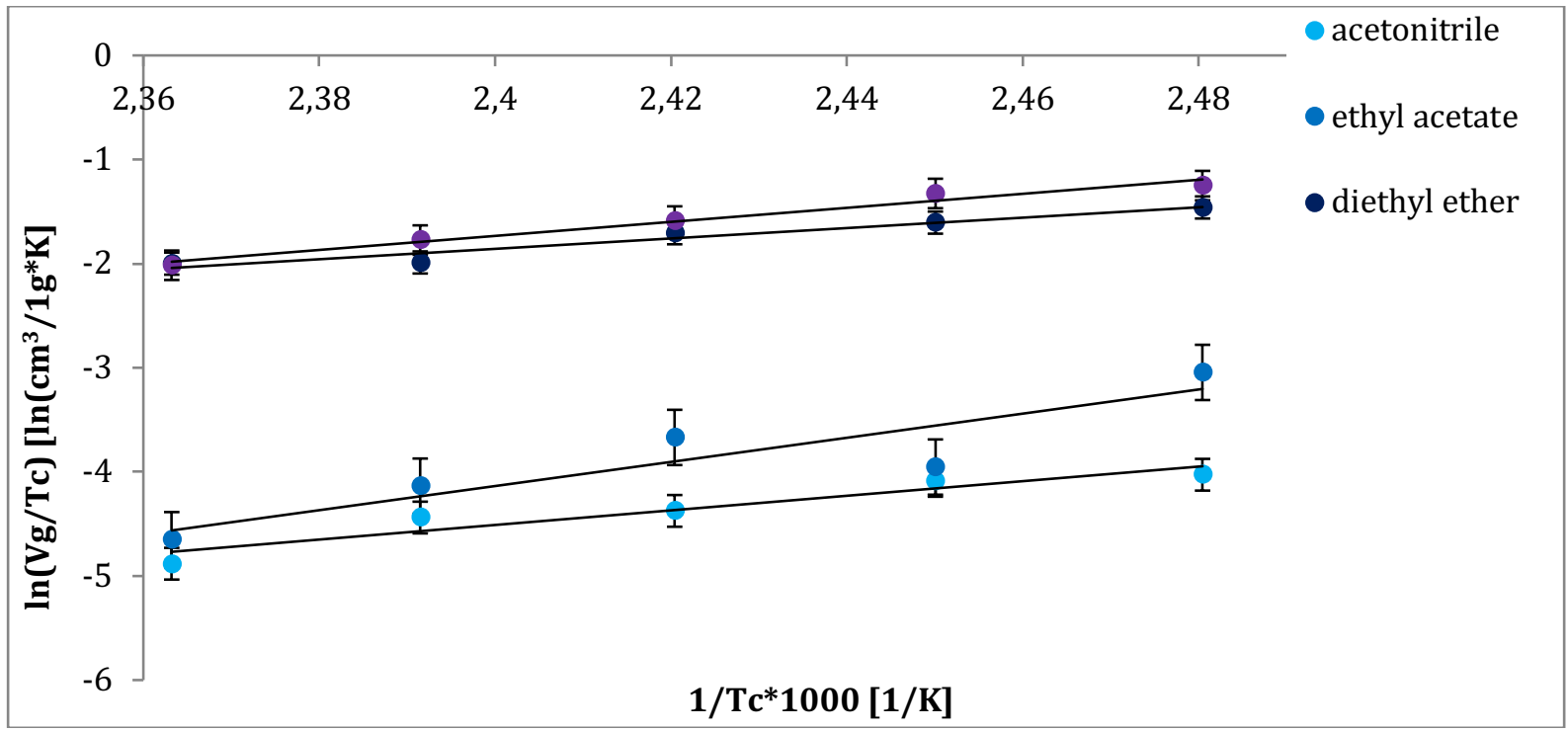

Fig. 3. The $\ln (\mathrm{Vg} / \mathrm{Tc})=f(1 / \mathrm{Tc})$ dependencies for the $\mathrm{GO}$ (acetonitrile, ethyl acetate, diethyl ether, tetrahydrofuran)

Source: Author's

The determined(by using equation (6)) values of the molar differential enthalpy and entropy of adsorption (vide collated in Table 2)which increase with the number of methylene groups in n-alkane chain. The existence of the linear dependencies between the molar differential entropy and enthalpy of adsorption confirm that during the elution processes the ideal, nonlinear conditions have been attained (Figs. 4 and 5). 
Table 2. The values of the molar differential entropy and enthalpy of adsorption for GO and rGO (the P4 function).

\begin{tabular}{|c|c|c|c|c|c|c|}
\hline \multirow{2}{*}{ Testing substances } & \multicolumn{3}{|c|}{$\mathbf{G O}$} & \multicolumn{3}{c|}{ rGO } \\
\cline { 2 - 6 } & $\begin{array}{c}\Delta \mathbf{H}_{\text {ADS }} \\
{[\mathbf{k J} / \mathbf{m o l}]}\end{array}$ & $\begin{array}{c}\Delta \mathbf{S}_{\text {ADS }} \\
{\left[\mathrm{J} / \mathbf{m o l}^{*} \mathrm{~K}\right]}\end{array}$ & $\mathbf{S D * 1 \mathbf { 0 } ^ { - 2 }}$ & $\begin{array}{c}\mathbf{\Delta} \mathbf{H}_{\text {ADS }} \\
{[\mathbf{k J} / \mathbf{m o l}]}\end{array}$ & $\begin{array}{c}\Delta \mathbf{S}_{\text {ADS }} \\
{\left[\mathrm{J} / \mathbf{m o l}^{*} \mathrm{~K}\right]}\end{array}$ & $\mathbf{S D}^{*} \mathbf{1 0}^{-2}$ \\
\hline n-pentane & -74.03 & -242.73 & 0.97 & -67.64 & -146.24 & 0.05 \\
\hline n-hexane & -69.96 & -229.00 & 0.34 & -64.74 & -120.71 & 1.24 \\
\hline n-heptane & -60.27 & -193.77 & 2.41 & -60.28 & -98.73 & 2.25 \\
\hline n-octane & -51.90 & -189.24 & 1.27 & - & - & - \\
\hline dichloromethane & -28.97 & -115.30 & 0.79 & -67.60 & -144.41 & 2.12 \\
\hline chloroform & -40.99 & -168.69 & 1.55 & -76.01 & -164.42 & 2.33 \\
\hline carbon tetrachloride & -76.83 & -250.10 & 0.28 & -83.55 & -188.90 & 0.27 \\
\hline acetonitrile & -3.28 & -73.69 & 0.46 & -55.46 & -116.24 & 1.87 \\
\hline ethyl acetate & -133.18 & -386.10 & 0.59 & -62.47 & -134.96 & 0.57 \\
\hline diethyl ether & -5.61 & -57.03 & 0.57 & -68.37 & -136.74 & 0.49 \\
\hline tetrahydrofuran & -51.83 & -170.70 & 2.07 & -50.41 & -47.87 & 0.04 \\
\hline
\end{tabular}

Source: Author's

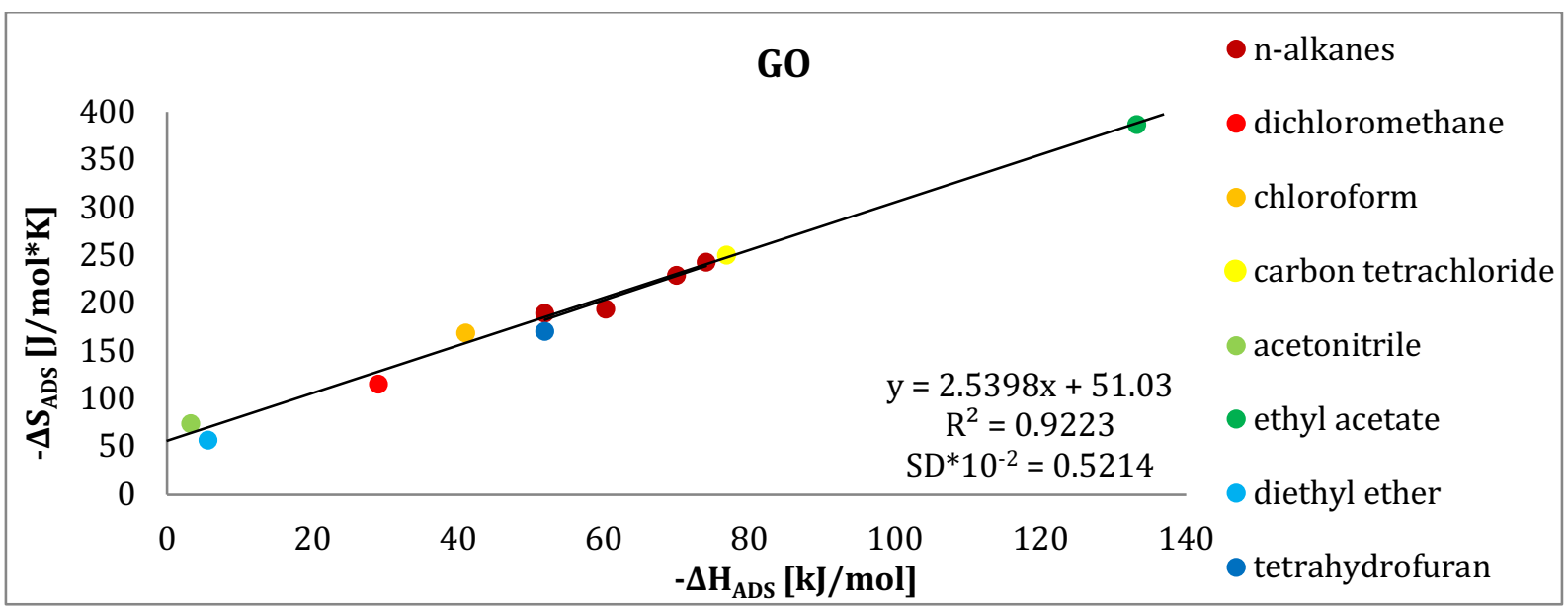

Fig. 4. The $-\Delta \mathrm{S}_{\mathrm{ADS}}=\mathrm{f}\left(-\Delta \mathrm{H}_{\mathrm{ADS}}\right)$ dependency for $\mathrm{GO}$ (the P4 function) Source: Author's



Fig. 5. The $-\Delta \mathrm{S}_{\mathrm{ADS}}=\mathrm{f}\left(-\Delta \mathrm{H}_{\mathrm{ADS}}\right)$ dependency for $\mathrm{rGO}$ (the $\mathrm{P} 4$ function) Source: Author's

The interpretation of the interactions between the graphene samples tested and the molecules of the testing substances can be interpreted as specific and nonspecific. The specific interactions are caused by the polar groups and nonspecific interactions are involved by methyl and methylene groups. Analysing Figs. 6 and 7, we 
can state that the specific interactions are stronger with the rGO sample.The dispersive component of the free energy of the liquid or testing substance injected was calculated by using equation 7 .

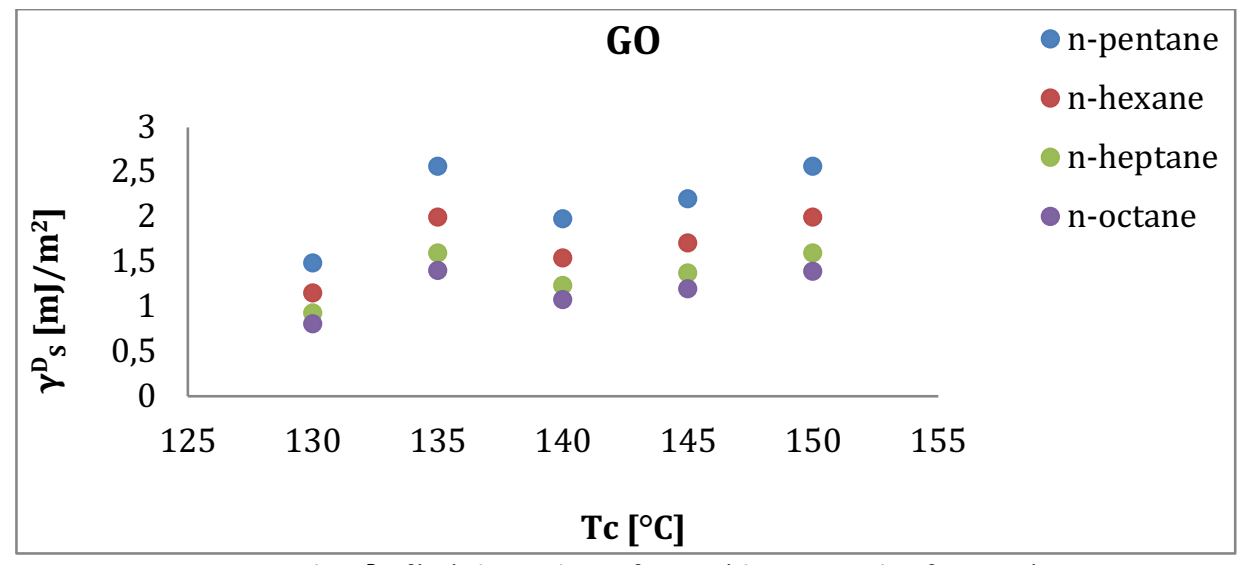

Fig. 6. The $\gamma^{D_{s}=f(T c)}$ dependency for $\mathrm{GO}$ (the ExtraVal4T function)

Source: Author's

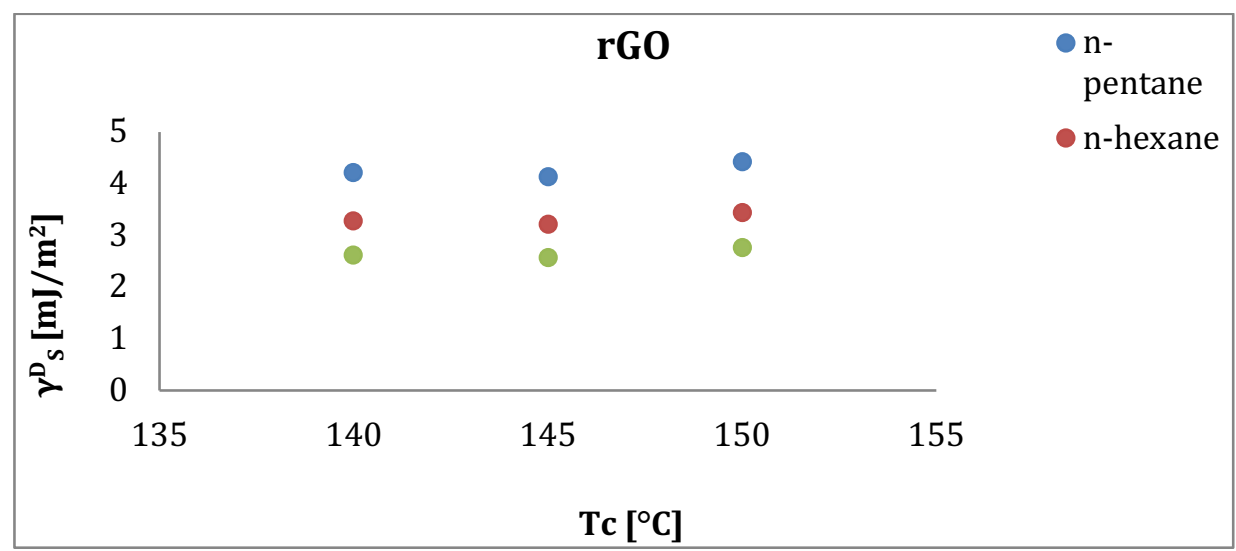

Fig. 7. The $\gamma^{\mathrm{D}} \mathrm{s}=\mathrm{f}(\mathrm{Tc})$ dependency for $\mathrm{rGO}$ (the ExtraVal4T function) Source: Author's

As it was mentioned previously, the specific interaction effects occur when the hydrogen bond, acid-base interactions and $\pi$-orbitals interactions are created. To estimate the specific component of the Gibbs free energy of adsorption, $\Delta G_{A D S}^{S P}$, it is necessary to determine the following dependencies $\Delta G_{A D S}=f(T c)$ (Figs 8, 9 and 10), $\Delta G_{A D S}=f\left(\omega * \sqrt{\gamma_{L}^{v d W}}\right.$ ) (Fig. 11, where $\omega$ is the sitting area for adsorbate molecule and $\gamma_{L}^{v d W}$ is the surface free energy of the pure phase [23]), $\Delta G_{A D S}=f\left(P_{D}\right)$ (Fig. 12, where $P_{D}$ is the molar deformation polarisation [17]) and $\Delta G_{A D S}=f\left(\Delta H_{V A P}\right)$ (Fig. 13, where $\Delta H_{V A P}$ is the enthalpy of vapourisation [17]), which must provide good linearity. The values of the specific component of the $\Delta G_{A D S}^{S P}$ magnitude are collated in Table 3. 


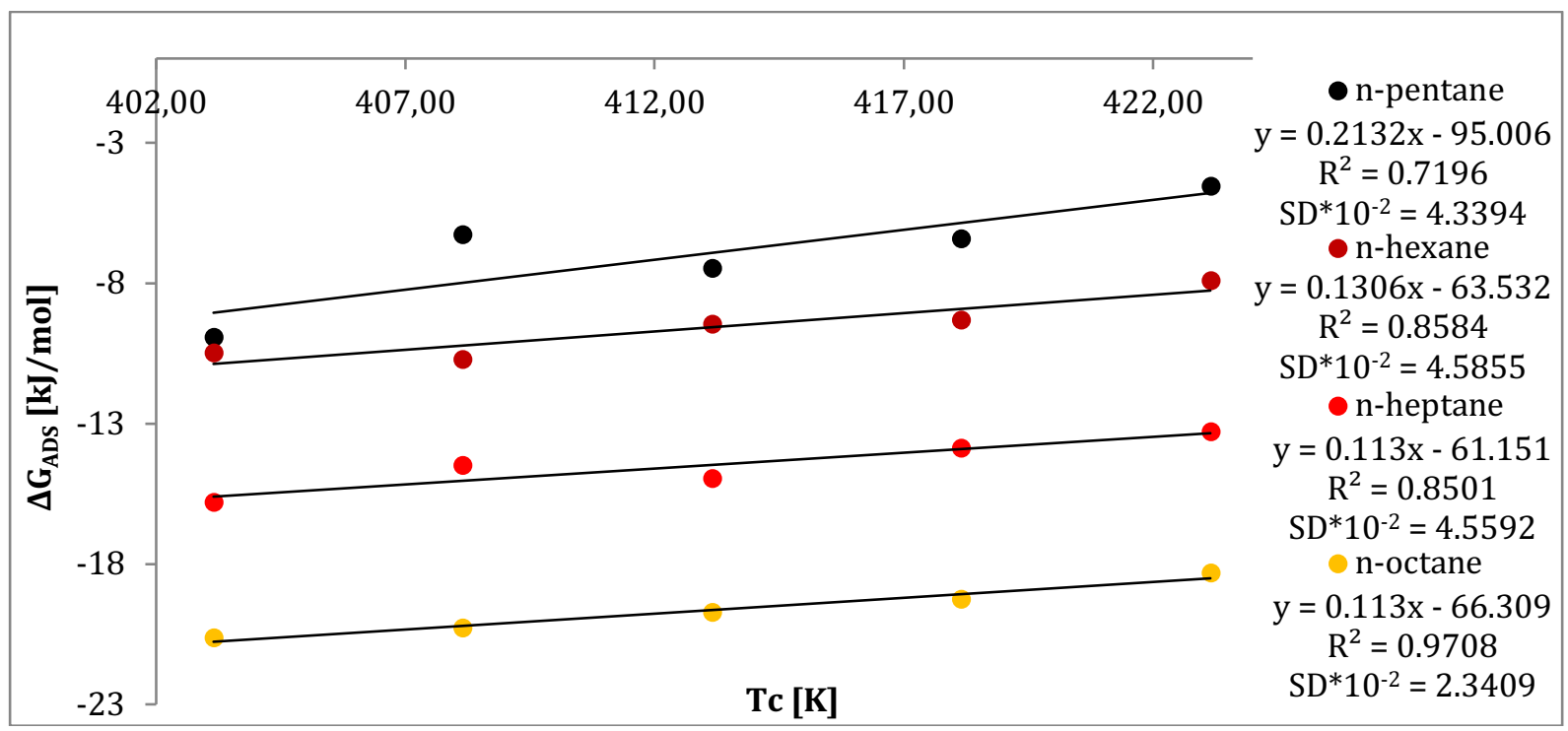

Fig. 8. The $-\Delta G_{A D S}=f(T c)$ dependency for $G O$ (n-alkanes; the ExtraVal4T function) Source: Author's



Fig. 9. The $-\Delta G_{A D S}=f(T c)$ dependency for $G O$ (dichloromethane, chloroform, carbon tetrachloride; the ExtraVal4T function) Source: Author's 


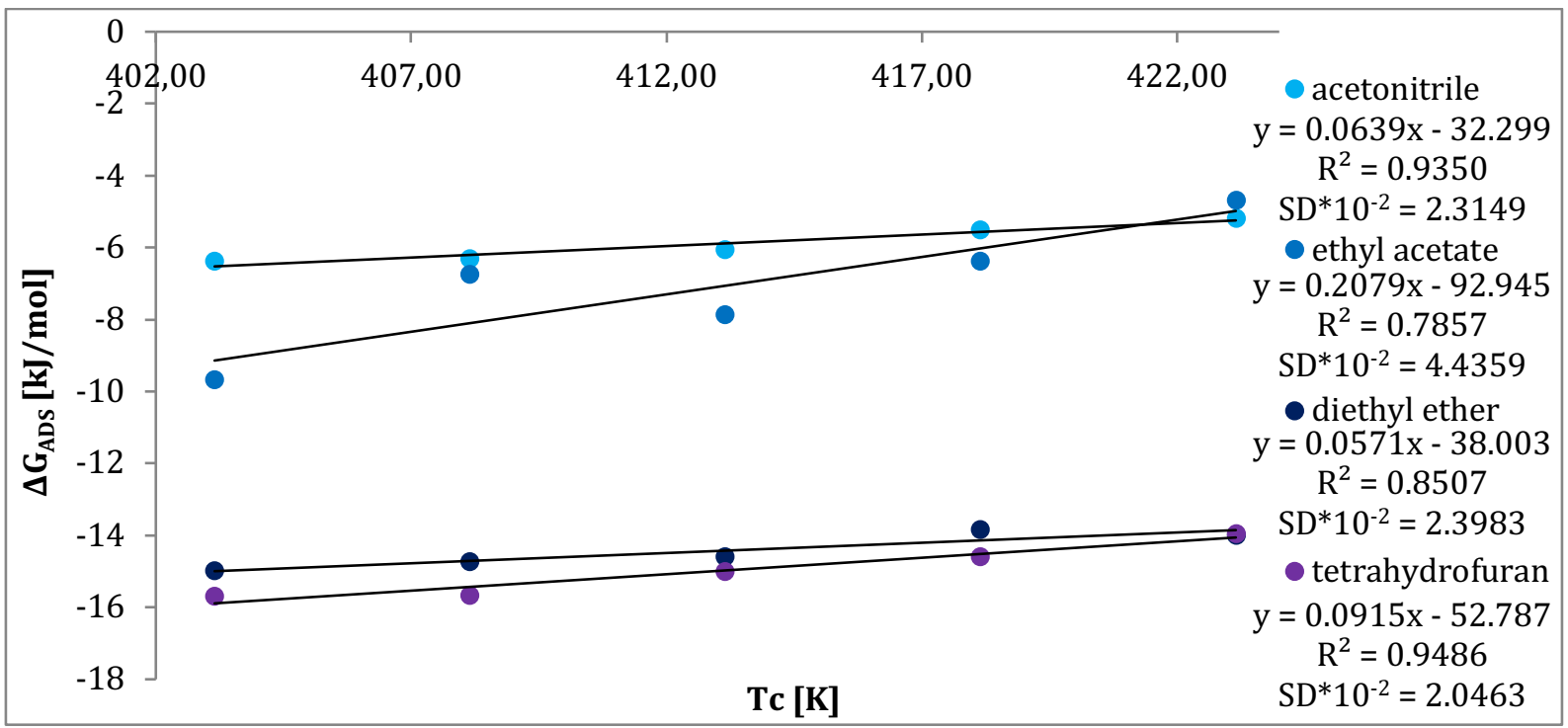

Fig. 10. The $-\Delta G_{A D S}=f(T c)$ dependency for $G O$ (acetonitrile, ethyl acetate, diethyl ether, tetrahydrofuran; the ExtraVal4T function)

Source: Author's

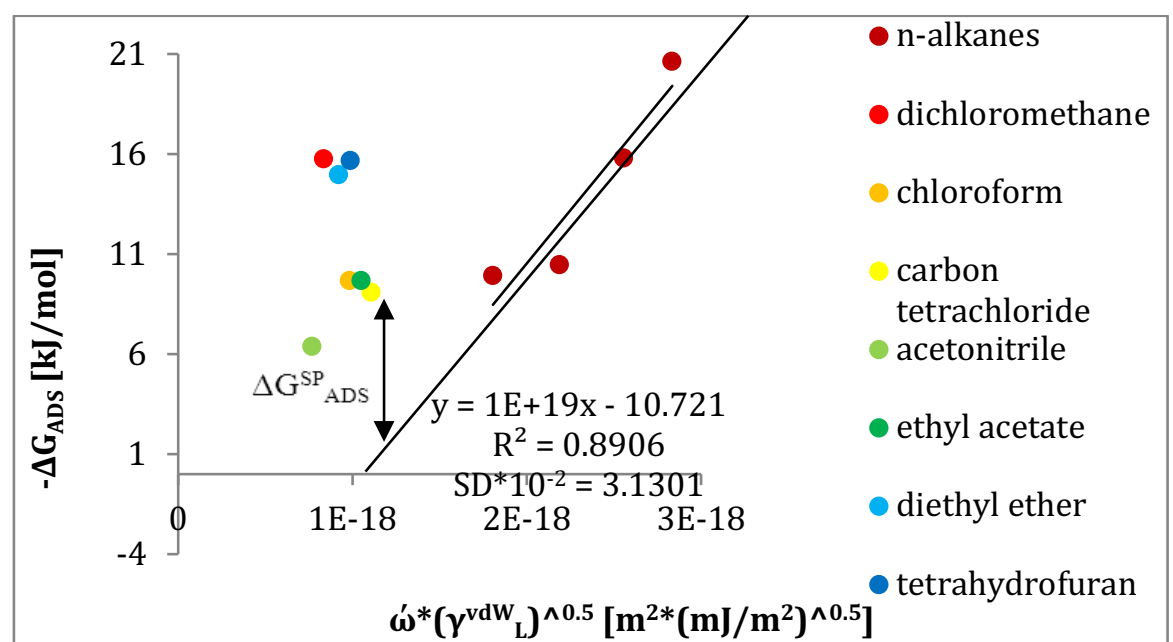

Fig. 11. The $\Delta G_{A D S}=f\left(\omega * \sqrt{\gamma_{L}^{v d W}}\right)$ dependency for GO (the ExtraVal4T function) Source: Author's 


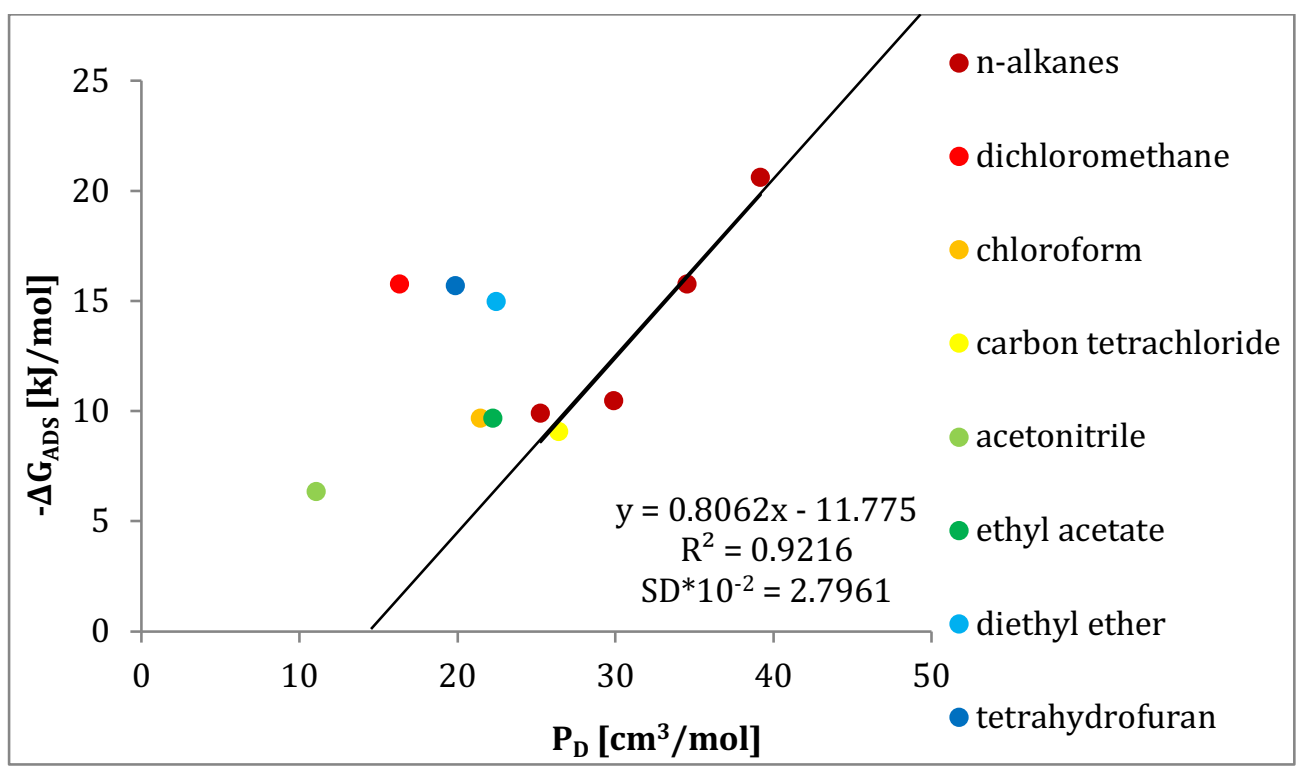

Fig. 12. The $\Delta G_{A D S}=f\left(P_{D}\right)$ dependency for $\mathrm{GO}$ (the ExtraVal4T function) Source: Author's

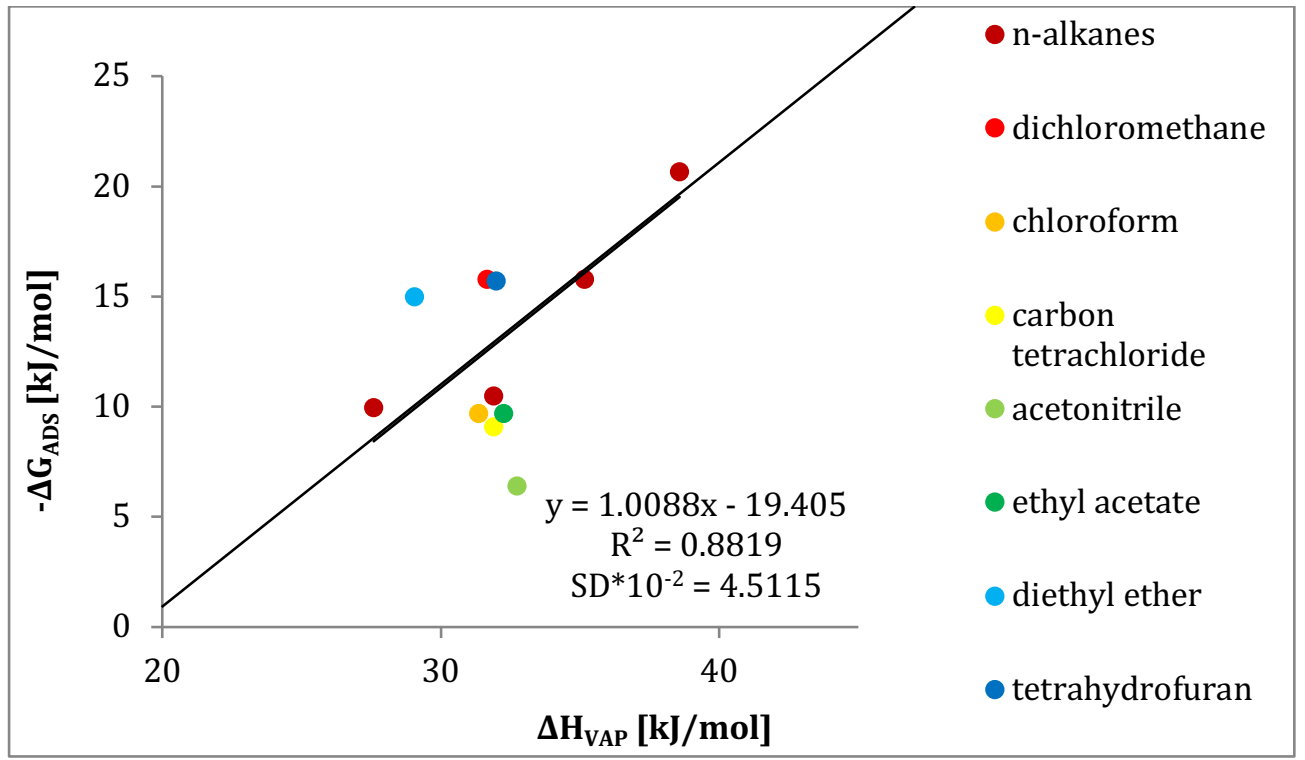

Fig. 13. The $\Delta G_{A D S}=f\left(\Delta H_{V A P}\right)$ dependency for $\mathrm{GO}$ (the ExtraVal4T function) Source: Author's 
Table 3.The values of the specific component of the $\Delta G_{A D S}^{S P}$ for $\mathrm{GO}$ and $\mathrm{rGO}$.



Source: Author's 
As was mentioned previously, in the characterization of the acceptor-donor properties of the materials, the identification of the component of the specific effects must be separated from all interactions.

It is possible on the basis of the thermodynamic data estimated for two groups of the testing substances, namely characterizing by acceptor (a Lewis acid, AN) and donor (a Lewis base, DN) properties. Gutmann's background developed by Riddle and Fowkes (i.e., the AN* and DN numbers) are very useful in the IGC tests of the aforementioned parameters. The values of the $\mathrm{AN}^{*}$ and $\mathrm{DN}$ parameters needed for the calculations are collated in Table 4.

Table 4. The Gutmann donor numbers and the Riddle-Fowkes acceptor numbers $[20,21]$

\begin{tabular}{|c|c|c|}
\hline Testing substances & DN $[\mathbf{k J} / \mathbf{m o l}]$ & AN* $[\mathbf{k J} / \mathbf{m o l}]$ \\
\hline dichloromethane & 0.0 & 16.3 \\
\hline chloroform & 0.0 & 22.6 \\
\hline carbon tetrachloride & 0.0 & 2.9 \\
\hline acetonitrile & 59.0 & 19.7 \\
\hline ethyl acetate & 71.5 & 7.5 \\
\hline diethyl ether & 80,3 & 5.9 \\
\hline tetrahydrofuran & 83.7 & 2.1 \\
\hline
\end{tabular}

Source: Author's

By applying the equations (8), (10) and also (11) and (12) it is possible to determine the values of the $K_{A}$ and $K_{D}$ parameters, which directly characterise the acceptor-donor properties of the tested column fillings.

The obtained results are collated in Table 5 and the exemplary plot for $\frac{\left(-\Delta H_{A D S}^{S P}\right)_{i}}{A N_{i}^{*}}=f\left(\frac{D N_{i}}{A N_{i}^{*}}\right)$ dependency is depicted in Fig. 14.

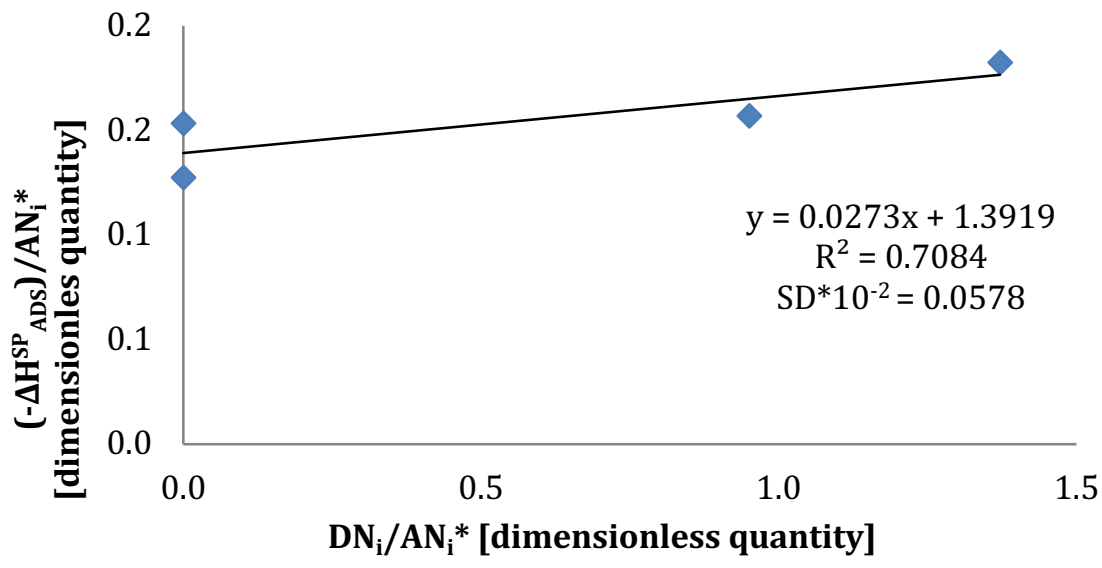

Fig. 14. The $\frac{\left(-\Delta H_{A D S}^{S P}\right)_{i}}{A N_{i}^{*}}=f\left(\frac{D N_{i}}{A N_{i}^{*}}\right)$ dependence (the ExtraVal4T function) Source: Author's 
Table 5. The obtained results of the $\mathrm{K}_{A}$ and $\mathrm{K}_{\mathrm{D}}$ parameters and $\mathrm{K}_{\mathrm{A}} / \mathrm{K}_{\mathrm{D}}$ ratio for the description by the ExtraVal4T function.

\begin{tabular}{|c|c|c|c|c|}
\hline \multirow{2}{*}{ Parameter } & \multicolumn{2}{|c|}{ GO } & \multicolumn{2}{|c|}{ rGO } \\
\hline & Equation 16 & Equation 17 & Equation 16 & Equation 17 \\
\hline \multicolumn{3}{|c|}{$\omega * \sqrt{\gamma_{L}^{v d W}} n$} & $\left.\frac{m J}{m^{2}}\right)$ & \\
\hline$K_{A}$ & 0.032 & 0.038 & 0.119 & 0.048 \\
\hline$K_{D}$ & 1.619 & 1.260 & 0.485 & 0.524 \\
\hline$K_{A} / K_{D}$ & 0.020 & 0.030 & 0.246 & 0.091 \\
\hline \multicolumn{5}{|c|}{$P_{D}\left[\mathrm{~cm}^{3} / \mathrm{mol}\right]$} \\
\hline$K_{A}$ & 0.025 & 0.031 & 0.107 & 0.037 \\
\hline$K_{D}$ & 1.428 & 1.074 & 0.319 & 0.358 \\
\hline$K_{A} / K_{D}$ & 0.017 & 0.029 & 0.338 & 0.103 \\
\hline \multicolumn{5}{|c|}{$\Delta \mathrm{H}_{\mathrm{VAP}}[\mathrm{kJ} / \mathrm{mol}]$} \\
\hline$K_{A}$ & 0.027 & 0.036 & 0.112 & 0.042 \\
\hline$K_{D}$ & 1.391 & 1.041 & 0.358 & 0.396 \\
\hline$K_{A} / K_{D}$ & 0.019 & 0.034 & 0.314 & 0.107 \\
\hline
\end{tabular}

Source: Author's

It can be easily recognized that the values of the $K_{A}$ and $K_{D}$ can be influenced by many factors, including the properties of the attached functional groups.

The aforementioned parameters expressed as the $K_{A} / K_{D}$ quotients allow relative characteristics of the surface properties of the materials tested [24]:

a) a surface with acidic properties:

$$
\frac{\mathrm{K}_{\mathrm{A}}}{\mathrm{K}_{\mathrm{D}}} \geq 1.1
$$

b) a surface with neutral properties:

$$
0.9<\frac{\mathrm{K}_{\mathrm{A}}}{\mathrm{K}_{\mathrm{D}}}<1.1
$$

c) a surface with basic properties:

$$
\frac{\mathrm{K}_{\mathrm{A}}}{\mathrm{K}_{\mathrm{D}}} \leq 0.9
$$

Analysing the $\mathrm{K}_{\mathrm{A}} / \mathrm{K}_{\mathrm{D}}$ values it is necessary to state that both oxidized and reduced graphene surfaces have donor properties. It can be caused by the method of synthesis of the samples. 


\section{Summary and conclusions}

The optimisation of the chromatographic conditions revealed that the sets of the $K_{A}, K_{D}$ and $K_{A} / K_{D}$ values obtained by the IGC method enable a deeper characteristic of the acceptor-donor properties of graphene samples. In our studies we confirmed that the intermolecular interactions of the probes with graphene materials were governed by acceptor-donor interactions as evidenced by Drago's studies. It also showed that the 'thermodynamic compensation effect' $\left[-\Delta \mathrm{S}_{A D S}=f\left(-\Delta \mathrm{H}_{A D S}\right)\right]$ can be accomplished for the ideal, nonlinear chromatographic conditions. In addition, it demonstrated that the tested samples of graphene, both oxidized and reduced, have donor properties, although the GO surface has stronger basic properties due the lone electron pairs of oxygen atoms.

The optimisation of the acceptor-donor tests for the graphene samples in this paper produce a wide range of information on the one hand, and as many adsorption tests, they are highly sensitive to the chromatographic condition on the other. Nevertheless, the way in which electrons are exchanged between the functionalities located in the structure of the graphene samples and the active sites of testing substances, now is not possible to elucidate. Thus, the exact description of the electron transfer mechanism is still a matter of methodical and thorough scientific debate.

\section{References}

[1] H.P. Boehm, A. Clauss, G.O. Fischer, U. Hofmann, Dünnste Kohlenstoff-Folien, Zeitsdirift für Naturforschung 17 b, Seite 150-153, 1961 (in German).

[2] A.K. Geim, K.S. Novoselov, The rise of graphene, Nature Materials 6 (2007)183-191.

[3] S. Mikhailov, Z. Koinov, Physics and applications of graphene theory, InTech, New York, 2011.

[4] D. Jiang, Z. Chen, Graphene chemistry: theoretical perspectives, John Wiley \& Sons Inc, United Kingdom, 2013.

[5] A.K. Geim, Graphene prehistory, Phys. Scr. T146 (2012) 014003 (4pp).

[6] S. Alwarappan, A. Kumar, Graphene-based nanomaterials: science and technology, CRC Press, 2013.

[7] K.I. Bolotin, K.J. Sikes, Z. Jianga, M. Klima, G. Fudenberg, J. Hone, P. Kim, H.L. Stormer, Ultrahigh electron mobility in suspended graphene, Solid State Communications 146, 9 (2008) 351-355.

[8] A.A. Balandin, S. Ghosh, W. Bao, I. Calizo, D. Teweldebrhan, F. Miao, C.N. Lau, Superior Thermal Conductivity of Single-Layer Graphene, Nano Lett. 8, 3(2008) 902-907.

[9] C. Lee, X. Wei, J.W. Kysar, J. Hone, Measurement of the Elastic Properties and Intrinsic Strength of Monolayer Graphene, Science 321, 5887 (2008) 385-388.

[10] S. Chowdhury, R. Balasubramanian, Three-dimensional graphene-based macrostructures for sustainable energy applications and climate change mitigation, Progress in Materials Science 90 (2017) 224-275.

[11] L.E.F. Foà Torres, S. Roche, J.-C. Charlier, Introduction to graphene-based nanomaterials: from electronic structure to quantum transport, Cambridge University Press, New York, 2014.

[12] W. Choi, J. Lee, Graphene synthesis and applications, CRC Press, Boca Raton, 2012.

[13] S. Stankovich, D.A. Dikin, R.D. Piner, K.A. Kohlhaas, A. Kleinhammes, Y. Jia, Y. Wu, S.T. Nguyen, R. S. Ruoff, Synthesis of graphene-based nanosheets via chemical reduction of exfoliated graphite oxide, Carbon 45 (2007) 1558-1565.

[14] TableCurve 2D: Automated curve fitting and equation discovery: version 5.01 for windows; user's manual. Richmond, CA: SYSTAT, 2002.

[15] Ł. Farczak, Chromatograficzne badania zredukowanego i utlenionego grafenu, WAT, Warszawa, 2015.

[16] H. Grajek, J. Paciura-Zadrożna, Z. Witkiewcz, Chromatographic characterisation of ordered mesoporous silicas. Part I. Surface free energy of adsorption, J. Chromatogr. A 1217 (2010) 3105-3115.

[17] M.C. Gutiérrez, S. Osuna, I. Baráibar, Solid surface mapping by inverse gas chromatography, J. Chromatogr. A 1087, 1-2 (2005) 142-149.

[18] M.C. Gutierrez, J. Rubio, F. Rubio, J.L. Oteo, Inverse gas chromatography: a new approach to the estimation of specific interactions, J. Chromatogr. A 845, 1-2 (1999) 53-66.

[19] H. Grajek, Ł. Farczak, T. Wawer, P. Jabłoński, M. Purchała, The characteristic of the adsorption and energetic properties of the oxidised and reduced graphene, Aparatura Badawcza I Dydaktyczna, 3 (2015) 224233.

[20] V. Gutmann, The donor-acceptor approach to molecular interactions, Plenum Press, New York, 1978.

[21] F.L. Riddle, F.M. Fowkes, Spectral shifts in acid-base chemistry. 1. van der Waals contributions to acceptor numbers, J. Am. Chem. Soc. 112, 9 (1990) 3259-3264. 
[22] R.S. Drago, G.C. Vogel, T.E. Needham, A Four-Parameter Equation for Predicting Enthalpies of Adduct Formation, Journal of the American Chemical Society 93, 23 (1971) 6014-6026.

[23] G.M. Dorris, D.G. Gray, Adsorption of n-alkanes at zero surface coverage on cellulose paper and wood fibers, J. Coll. Interface Sci. 77 (1980) 353.

[24] U. Panzer, H.P. Schreiber, On the Evaluation of Surface Interactions by Inverse Gas Chromatography, Macromolecules 25 (1992) 3633-3637. 